\title{
Adverse Events Sustained by Children in The Intensive Care Unit: Guiding local quality improvement
}

Christopher James, Carmel Delzoppo, James Tibballs, siva Namachivayam, Warwick butt

Paediatric Intensive Care Unit Melbourne, Victoria, Australia

Correspondence: Christopher.James@rch.org.au

ABSTRACT

Objective: To determine the frequency, nature and consequence of adverse events sustained by children admitted to a combined general and cardiac paediatric intensive care unit (PICU).

Design: Retrospective analysis of data collected between January 1st 2008 and December 31st 2017 from PICU.

Setting: The Royal Children's Hospital, a paediatric tertiary referral centre in Melbourne, Victoria, Australia. The PICU has thirty beds.

Results: During the study period, PICU received 15208 admissions, of which $73 \%$ sustained at least one adverse event with a frequency of 67 adverse events per 100 PICU-days and 3 per admission. One adverse event was sustained for every 35 hours of care. The risk of an adverse event was highest in children less than a month of age, or if mechanically ventilated, a high Pediatric Index of Mortality (PIM2) score,

\section{INTRODUCTION}

Critically ill children requiring admission to a pediatric intensive care unit (PICU) are at risk of adverse events; from the procedures and technology associated with critical care medicine, and from their underlying disease and its progression. longer PICU length of stay, had a pre-existing disability or a high risk adjustment for congenital heart surgery (RACHS) score. Those patients who sustained an adverse event, as compared to those who did not, were mechanically ventilated for longer ( $80 \mathrm{hrs} \mathrm{Vs.} 7$ $h r s, p=<0.001$ ), had a longer PICU length of stay (131 hrs Vs. 35 hrs, $p=<0.001$ ), had a longer hospital length of stay (484 hrs Vs. 206 hrs, $\mathrm{p}=<0.001)$ and had a higher mortality rate ( $3 \%$ vs. $0.1 \%, p=<0.001)$.

Conclusion: Whilst admission to PICU is an essential aspect of care for many patients, the risk of adverse events is high and is associated with significant clinical consequences. Monitoring of adverse events as part of quality improvement enables targeted intervention to improve patient safety.

Keywords: quality improvement, paediatric, intensive care, adverse events

Adverse events arising as a consequence of care in an intensive care unit (ICU) were first described by Abramson and colleagues [1] in 1980. Despite improved survival and outcome of critically ill children cared for in PICU, adverse event rates remain high [2-4]. Specific data relating to the nature of adverse events 
that occur is needed in order to improve the safety of patients and optimise the quality of care delivered in the PICU.

The aim of this study was to analyse the frequency, nature and consequence of adverse events arising during PICU admission at our institution. We report how the frequency of central line associated bloodstream infection (CLABSI), ventilator associated pneumonia (VAP) and accidental extubation rates, key performance indices reported by most ICUs, changed over the study period to highlight progress in patient safety.

The study received ethical approval from the institutions Human Research Ethics Committee (HREC 34221C).

\section{MATERIALS AND METHODS}

The Royal Children's Hospital (RCH), Melbourne serves the population of the States of Victoria, Tasmania and southern New South Wales, Australia. The combined general and cardiac PICU has thirty beds and admitted 1719 patients in 2017 (7593 patient days).

Three dedicated data collection nurses from the PICU quality, data and research team prospectively record data on patient admissions, adverse events sustained subsequent to admission and discharges in the 4D database STATIC?, an intensive care specific relational database. Data related to PICU admissions and subsequent adverse events was extracted from 1st January 2008 to 31st December 2017 for analysis. Adverse events were recorded as being major or minor in nature and patients grouped by age, preexisting function, severity of illness on admission (Paediatric Index of Mortality, PIM2), risk adjustment for congenital heart surgery (RACHS) and by length of PICU stay.

\section{Definitions}

An adverse event is defined as an injury resulting from a medical intervention $[5,6]$ or an unfavorable consequence of disease. A list of adverse events was compiled by amalgamating hospital and publically available sources [7,8] (Supplemental Table 1). Adverse events were defined as major if they resulted in significant medical or surgical intervention, permanent disability, or unexpected or preventable death, as decided by routine monthly departmental morbidity and mortality review meetings.

A ventilator associated pneumonia (VAP) was identified using a combination of radiologic, clinical and laboratory criteria in a patient intubated and ventilated within 48 hours of onset, as defined in Victorian State guidelines [9]. Our definition of central line associated bloodstream infection (CLABSI) is a laboratory confirmed bloodstream infection in a patient where a central line is in place for greater than 48 hours, as defined by the Australian Commission on Safety and Quality in Healthcare [10]. We define accidental extubation as a premature and unplanned removal of the endotracheal tube by the action of either the patient or a healthcare professional.

Pre-existing function is assessed at admission using the modified Glasgow outcome score (MGOS), a global assessment tool of independent living and social integration for children older than one month of age [11]. The pre-existing function obtained by the MGOS divides children into five categories: normal, functionally normal (physically and intellectually normal) but requiring medication or medical supervision, mild disability but likely to lead an independent existence, moderate 
disability and dependent on care, and severe disability and totally dependent on care.

\section{Statistical analysis}

Analyses were performed using Stata v13.1 (StataCorp. College Station, TX). Continuous patient outcomes were compared using MannWhitney $U$ tests and binary outcomes using Chi-squared tests.

\section{RESULTS}

Over the ten-year period, 10417 patients accounted for 15208 admissions to the PICU. Of all admissions, $73 \%$ sustained at least one adverse event during their admission at a frequency of 67 adverse events per 100 PICUdays and 3 per admission (Table 1). One adverse event was sustained every 35 hours of care. Thirteen percent of adverse events were major (Table 2). Major adverse events occurred 8 times per 100-PICU days, 0.4 times per admission and for every 288 hours of care.

Of all patients admitted to PICU during the study period, 10028 (66\%) required mechanical ventilation and these patients had a higher incidence of adverse events (57\%) compared to those not requiring mechanical ventilation (16\%). The proportion of patients sustaining an adverse event was highest in those less than a month of age (89\%). The likelihood of an adverse event increased as PICU length of stay increased and adverse events were sustained more frequently in patients with higher RACHS and PIM2 scores as well as higher pre-existing disability (Table 3 ).

Those patients who sustained an adverse event during their PICU admission, as compared to those who did not, had (if ventilated) a longer mean duration of ventilation ( $80 \mathrm{hrs}$ vs. $7 \mathrm{hrs}, \mathrm{p}=<0.001$ ), had a longer mean PICU length of stay (131 hrs vs. 35 hrs, $p=<0.001$ ), had a longer mean hospital length of stay ( 484 hrs vs. $206 \mathrm{hrs}, \mathrm{p}=<0.001$ ) and had a higher mortality rate ( $3 \%$ vs. $0.1 \%$, $\mathrm{p}=<0.001$ )(Table 4). Patients who sustained a major adverse event, when compared to those who sustained none, had an even longer mean duration of ventilation (212 hrs vs. $7 \mathrm{hrs}$, $p=<0.001$ ), had a longer mean PICU length of stay ( 300 hrs vs. 35 hrs, $p=<0.001$ ), had a longer mean hospital length of stay (921 hrs vs. 212 hrs, $\mathrm{p}=<0.001$ ) and had a higher mortality rate $(4.4 \%$ vs. $0.2 \%, p=<0.001)$ (Table 4$)$. The relative risk of death if any adverse event was sustained was 10.7 (95\% $\mathrm{Cl} 6.5-17.6)$ and 28.5 $(95 \% \mathrm{Cl} 17-47)$ if the adverse event was major.

Supplemental Table 1 outlines the specific adverse events by category and whether the adverse event was the result of a medical intervention or an unfavourable consequence of disease. The relative risk of death if an adverse event was the result of a medical intervention was $19(95 \% \mathrm{Cl} 11-32)$ and 11 $(95 \% \mathrm{Cl} 7-18)$ if the adverse event was an unfavourable consequence of disease (Supplemental Table 2). The frequency of adverse events by RACHS score, PIM2 score, pre-existing patient function, age and PICU length of stay are detailed in Supplemental tables 3-7.

During the first two years of the study period, the central line associated bloodstream infection (CLABSI) rate on our ICU was 2.75 per 1000 central line days. This decreased to 1.9 per 1000 central line days in the last two years of the study period $p>0.05$ ). Similarly, the incidence of ventilator associated pneumonia (VAP) was 3.55 per 1000 ventilator days in the first two years of the study, decreasing to 1.2 per 1000 ventilator days in the final two years 
$(p>0.05)$. The incidence of accidental extubation was 0.33 per 100 ventilator days at the beginning of the study period and 0.44 per 100 ventilator days by the end ( $p>0.05$ ).

\section{DISCUSSION}

While sick children undoubtedly benefit from having access to a PICU [12], once admitted they are at risk of adverse events arising from both their illness and the care they receive. In this study, patients less than one month of age, those requiring mechanical ventilation and with high RACHS or PIM2 scores, as well as those with pre-existing disabilities were more likely to sustain an adverse event. Patients who sustained adverse events were found to have longer PICU stays, but we are unable to determine whether longer stays are attributable to the consequences of adverse events or whether adverse events are more likely to occur during a longer PICU admission. That adverse events were sustained more frequently in the youngest of patients is not surprising considering that procedures are often more challenging in this population. Similarly, those children whose illness is the most severe, with high PIM2 scores or following more complex cardiac surgery, are more likely to suffer from unfavorable consequences of their disease and are more likely to require multiple procedures. Compared to patients who did not sustain an adverse event, those who did were mechanically ventilated longer, had a longer PICU length of stay, longer hospital length of stay and were at higher risk of death.

The frequency of adverse events that we report is consistent with data from other PICUs. A previous single-center PICU study reported that $59 \%$ of their patients suffered at least one adverse event, at a rate of 52.7 per
100 PICU-days and 1.95 per patient [2] and a multicenter PICU study found an adverse event rate of 28.6 per 100 PICU-days and 2.03 per patient [3]. Reported rates from adult ICU literature range from $14 \%$ to $31 \%$ ( 4.5 to 10 events per 100 ICU-days) [13-15]. Hooper and Tibballs [16] investigated the incidence of adverse events in our PICU over a three-month period in 2011 by examining 60 randomly selected patient records and identifying adverse events using a Trigger Tool. They found the incidence of adverse events was 59.9 per 100 PICU-days, consistent with our finding of 67 per 100 PICU-days.

Hospital-acquired infections have been highlighted in recent years as a particularly important aspect of patient safety [17] and are used on our PICU as key performance indices. Despite this they were the leading cause of adverse events on our PICU. Deviations from safe practice standards are associated with higher infection rates [18] and in 2011 we put in place teaching programs targeting practices such as hand-hygiene compliance [19] and full sterile barrier precaution during catheter insertions [20,21]. The incidence of CLABSI fell from 2.75 to 1.9 per 1000 central line days and that of VAP from 3.55 to 1.2 per 1000 ventilator days. This highlights progress that has been made in recent years regarding patient safety. Also noteworthy is that in 1992 the rate of accidental extubation on our PICU was 1.26 per 100 ventilator days [22], which was comparable to other PICU reports $[23,24]$. The rate of accidental extubation over the period of this study was 0.46 per 100 ventilator days.

The occurrence of an adverse event does not necessarily imply medical negligence $[25,26]$. Brennan and colleagues [27] showed that the occurrence of adverse events does not correlate with the quality of medical care and 
that patients in certain specialties, such as intensive care, are at increased risk.

A strength of this study is that the data was collected prospectively from a large PICU over a relatively long period. The study has important implications for safety improvement in the critical care setting. The type and frequency of adverse events sustained can help guide policy making decisions at a local level, as well as for those intensive care units with similar patient mix. Examples of this include targeted interventions based on the assessment of preventable adverse events, and the development of protocols and guidelines to reduce preventable adverse events such as infection, procedure related incidents and pressure sores. Preventable adverse events are often associated with systems-related deficiencies which can be corrected using ICU or hospital-wide changes in practice. This has been shown to be the case in previous studies not restricted to critical care $[28,29]$. Data on our key performance indices may be useful to other units for comparative purposes.

The study has several limitations. Firstly, we report findings from a single centre. Although the period of study is quite long, our patient mix consisting of general paediatric and cardiac ICU patients, practices and protocols will differ from other institutions making comparison difficult. In addition, our results may not be directly comparable to other institutions due to differing definitions of what constitutes an adverse event. We included complications associated with underlying disease, such as hyperkalemia in a patient with rhabdomyolysis. Whereas some will argue that these are frequently unavoidable, we felt that they still put the patient at risk and should be recorded to aid target intervention. We did not collect data on medication errors which is a weakness of the study. Accurate measurement of medication errors requires the examination of every patient's drug chart each day. Whilst we monitor medication errors in our PICU with regular audits, resources would not allow us to perform this daily.

Future research should concentrate on methods to create a culture in the critical care setting where discussing patient safety and reporting adverse events is encouraged at a unit and hospital level to reduce the incidence of adverse events on PICU and improve outcome.

\section{CONCLUSIONS}

Whilst admission to PICU provides life-saving care for patients, adverse events are common and may be associated with significant morbidity and mortality in our PICU. Adverse events decreased in frequency and severity over the study period. Monitoring of adverse events as part of quality improvement enables targeted intervention to improve patient safety.

\section{FUNDING}

None 


\section{References}

1. Abramson NS, Wald KS, Grenvik AN et al: Adverse occurrences in intensive care units. JAMA 1980;244:1582-1584

2. Larsen GY, Donaldson AE, Parker HB et al: Preventable harm occurring to critically ill children. Pediatr Crit Care Med 2007;8:33-336

3. Agarwal S, Classen D, Larsen G et al: Prevalence of adverse events in pediatric intensive care units in the United States. Pediatr Crit Care Med 2010;11:568-578 4. Benavidez O, Gauvreau K, Del Nido P et al: Complications and Risk Factors for Mortality During Congenital Heart Surgery Admissions. Ann Thorac Surg 2007;84:147-55

5. Institute of Medicine: To Err is Human; Building a Safer Health System. National Academy Press,

Washington, DC, 2000

6. Committee on Quality of Health Care in America. Crossing the Quality Chasm: A New Health System for the 21st Century. National Academy Press, Washington, DC, 2001

7. Griffin FA, Resar RK: IHI Global Trigger Tool for Measuring Adverse Events, 2nd ed. Cambridge, MA: Institute for Health Improvement 2009.

8. Child health Corporation of America. PICU Trigger Instruction Manual. Available at http://www.chca.com/triggers/index.html Accessed June 27, 2016

9. Victorian Nosocomial Infection Surveillance System. Intensive Care Unit (ICU): Ventilator Associated Pneumonia (VAP). Available at http://www.vicniss.org.au Accessed January 3, 2017 10. Australian Commission on Safety and Quality in Healthcare. Implementation Guide for Surveillance of Central Line Associated Bloodstream Infection. Available at https://www.safetyandquality.gov.au/ourwork/healthcare-associated-infection/national-haisurveillance-initiative/surveillance-initiativepublications/ Accessed January 3, 2017

11. Fiser DH: Assessing the outcome of pediatric intensive care. J Pediatr 1992;121(1):68-74 12. Pearson G, Shann F, Barry P et al: Should paediatric intensive care be centralized? Trent versus Victoria. Lancet 1997;349:1213-1217

13. Rubins HB, Moskowitz MA: Complications of care in a medical intensive care unit. J Gen Intern Med 1990;5:104-109

14. Rothschild JM, Landrigan CP, Cronin JW et al: The Critical Care Safety Study: The incidence and nature of adverse events and serious medical errors in intensive care. Crit Care Med 2005;33:1694-1700

15. Girauld T, Dhainaut J-F, Vaxelaire J-F et al: latrogenic complications in adult intensive care units: a prospective two-center study. Crit Care Med 1993;21:40-51

16. Hooper A, Tibballs J: Comparison of a Trigger Tool and voluntary reporting to identify adverse events in a paediatric intensive care unit. Anaesth Intensive Care 2014;42:199-206

17. Gerberding JL: Hospital-onset infections: A patient safety issue. Ann Intern Med 2002;137:665-670
18. Burke JP: Patient safety: infection control: A problem for patient safety. N Engl J Med 2003;348:651-656 19. Doebbeling BN, Stanley GL, Sheetz CT et al: Comparative efficacy of alternative hand-washing agents in reducing nosocomial infections in intensive care units. N Engl J Med 1992;327:88-93

20. Raad II, Hohn DC, Gilbreath BJ et al: Prevention of central venous catheter-related infections by using maximal sterile barrier precautions during insertion. Infect Control Hosp Epidemiol 1994;15(4:Pt 1):1-8 21. Berenholtz SM, Pronovost PM, Lipsett PM et al: Eliminating catheter-related bloodstream infections in the intensive care unit. Crit Care Med 2004;32:20142020

22. Rivera R, Tibballs J: Complications of endotracheal intubation and mechanical ventilation in infants and children. Crit Care Med 1992;20:193-199 23. Stambouly JJ, McLaughlin LL, Mandel FS et al: Complications of care in a pediatric intensive care unit: a prospective study. Intensive Care Med 1996;22:10981104

24. Little LA, Koenig JC, Newth CJ: Factors affecting accidental extubations in neonatal and paediatric intensive care patients. Crit Care Med 1990;18:163-165 25. Stambouly JJ, Pollack MM: latrogenic illness in pediatric critical care. Crit Care Med 1990;18:1248-1251 26. Kane RL: latrogenesis: just what the doctor ordered. J Community Health 1980;5:149-158

27. Brennan TA, Leape LL, Laird NM et al: Incidence of adverse events and negligence in hospitalized patients. Results of the Harvard Medical Practice Study I. N Engl J Med 1991;324:370-376

28. Leape LL, Brennan TA, Laird NM et al: The nature of adverse events in hospitalized patients. Results of the Harvard Medical Practice Study II. N Engl J Med 1991;324:377-384

29. Gawande AA, Thomas EJ, Zinner MJ et al: The incidence and nature of surgical adverse events in Colorado and Utah in 1992. Surgery 1999;126:66-75 
Table 1: Adverse events by year

\begin{tabular}{|c|c|c|c|c|c|c|c|c|c|c|c|}
\hline & 2008 & 2009 & 2010 & 2011 & 2012 & 2013 & 2014 & 2015 & 2016 & 2017 & Total \\
\hline Total admissions & 1213 & 1273 & 1352 & 1360 & 1392 & 1682 & 1721 & 1758 & 1738 & 1719 & 15208 \\
\hline Total days of care & 5388 & 5182 & 5888 & 6243 & 6347 & 7195 & 7862 & 7436 & 7799 & 7593 & 66933 \\
\hline $\begin{array}{c}\text { All adverse } \\
\text { events }\end{array}$ & 4215 & 4502 & 4323 & 4051 & 4100 & 4166 & 4474 & 4492 & 5195 & 5520 & 45038 \\
\hline $\begin{array}{c}\text { Major adverse } \\
\text { events }\end{array}$ & 539 & 506 & 611 & 528 & 509 & 497 & 567 & 576 & 583 & 616 & 5532 \\
\hline $\begin{array}{c}\text { All adverse } \\
\text { events per } 100 \\
\text { days of care }\end{array}$ & 78 & 87 & 73 & 65 & 65 & 58 & 57 & 60 & 67 & 73 & 67 \\
\hline $\begin{array}{l}\text { Major adverse } \\
\text { events per } 100 \\
\text { days of care }\end{array}$ & 10 & 10 & 10 & 8 & 8 & 7 & 7 & 8 & 7 & 8 & 8 \\
\hline $\begin{array}{l}\text { All adverse } \\
\text { events per } \\
\text { admission }\end{array}$ & 3.5 & 3.5 & 3.2 & 3.0 & 2.9 & 2.5 & 2.6 & 2.6 & 3.0 & 3.2 & 3.0 \\
\hline $\begin{array}{l}\text { Major adverse } \\
\text { events per } \\
\text { admission }\end{array}$ & 0.4 & 0.4 & 0.5 & 0.4 & 0.4 & 0.3 & 0.3 & 0.3 & 0.3 & 0.4 & 0.4 \\
\hline
\end{tabular}

Table 2: Adverse events by category

\begin{tabular}{|c|c|c|c|}
\hline Category & Major & Minor & Total \\
\hline Abdominal & 419 & 1905 & 2324 \\
\hline Cardiac arrest & 386 & 0 & 386 \\
\hline Cardiovascular & 610 & 6057 & 6667 \\
\hline Central Nervous System & 528 & 147 & 675 \\
\hline Fluid and electrolyte & 1 & 16628 & 16629 \\
\hline Haematological & 529 & 7893 & 8422 \\
\hline Infection & 961 & 1439 & 2400 \\
\hline Pressure area & 286 & 0 & 286 \\
\hline Procedure related & 229 & 1653 & 1882 \\
\hline Respiratory & 1596 & 3784 & 5380 \\
\hline Surgery related & 373 & 0 & 373 \\
\hline Total & 5918 & 39506 & 45038 \\
\hline
\end{tabular}


Table 3: Patient demographics and frequency of adverse events 2008 to 2017

\begin{tabular}{|c|c|c|c|}
\hline \multicolumn{2}{|c|}{ All admissions (n) } & No adverse event (per & Adverse event (per 100 \\
\hline \multirow{2}{*}{ Admission } & Elective (n1903) & 12 & 205 \\
\hline & Emergency (n6105) & 49 & 399 \\
\hline \multirow{4}{*}{ PIM2 } & $<1(n 1649)$ & 37 & 112 \\
\hline & 1 to 5 (n7409) & 20 & 306 \\
\hline & $5-15(n 1541)$ & 3 & 121 \\
\hline & $>15(n 698)$ & 0.08 & 66 \\
\hline \multirow{6}{*}{ RACHS } & RACHS 1 (n518) & 0.7 & 10 \\
\hline & RACHS 2 (n1622) & 3 & 48 \\
\hline & RACHS 3 (n1903) & 2 & 89 \\
\hline & RACHS 4 (n655) & 0.4 & 62 \\
\hline & RACHS 5 (n11) & 0 & 2 \\
\hline & RACHS 6 (n163) & 0 & 35 \\
\hline \multirow{6}{*}{$\begin{array}{l}\text { Pre-existing function on } \\
\text { admission }\end{array}$} & Normal (n2918) & 16 & 87 \\
\hline & Functionally normal (n3815) & 14 & 96 \\
\hline & Mild disability (n3669) & 11 & 138 \\
\hline & Moderate disability (n1853) & 9 & 86 \\
\hline & Severe disability (n1006) & 7 & 44 \\
\hline & $<1$ month age (n1947) & 4 & 153 \\
\hline \multirow{4}{*}{ Age } & $<1$ month (n1947) & 26 & 153 \\
\hline & 1-12 months (n4442) & 24 & 175 \\
\hline & $1-5$ years $(n 3981)$ & 19 & 114 \\
\hline & $>5$ years $(n 4838)$ & 16 & 162 \\
\hline \multirow{3}{*}{ ICU LOS category } & $<7$ days (n12926) & 57 & 217 \\
\hline & 7-21 days (n1804) & 4 & 200 \\
\hline & >21 days (n478) & 0 & 187 \\
\hline \multicolumn{2}{|c|}{ Invasive Ventilation (n10028) } & 23 & 537 \\
\hline
\end{tabular}

PIM: Paediatric Index of Mortality (predicted \% risk of death); RACHS: Risk Adjustment in Congenital Heart Surgery; ICU: Intensive Care Unit; LOS: Length of Stay 
Table 4: Comparison of duration of mechanical ventilation, mean ICU and hospital length of stay and mortality for patients who encountered an adverse event compared with those who did not

\begin{tabular}{|c|c|c|c|c|c|c|c|c|c|}
\hline & \multicolumn{3}{|c|}{ All admissions (n15208) } & \multicolumn{3}{|c|}{ Major (n6918) } & \multicolumn{3}{|c|}{ Minor (n12419) } \\
\hline & $\begin{array}{c}\text { Adverse } \\
\text { event } \\
(\mathrm{n} 11,066)\end{array}$ & $\begin{array}{c}\text { No } \\
\text { adverse } \\
\text { event } \\
(\mathrm{n} 4,142)\end{array}$ & $\begin{array}{c}\text { P- } \\
\text { value }\end{array}$ & $\begin{array}{l}\text { Major } \\
\text { (n2776) }\end{array}$ & $\begin{array}{c}\text { None } \\
\text { (n4142) }\end{array}$ & $\begin{array}{c}\text { P- } \\
\text { value }\end{array}$ & $\begin{array}{l}\text { Minor } \\
\text { (n8277) }\end{array}$ & $\begin{array}{c}\text { None } \\
\text { (n4142) }\end{array}$ & $\begin{array}{c}\text { P- } \\
\text { value }\end{array}$ \\
\hline $\begin{array}{c}\text { Mean } \\
\text { Invasive } \\
\text { Ventilation }\end{array}$ & 79 & 7 & $<0.001$ & 212 & 7 & $<0.001$ & 35 & 7 & $<0.001$ \\
\hline $\begin{array}{c}\text { Mean ICU } \\
\text { LOS }\end{array}$ & 131 & 35 & $<0.001$ & 300 & 35 & $<0.001$ & 75 & 35 & $<0.001$ \\
\hline $\begin{array}{c}\text { Mean } \\
\text { Hospital } \\
\text { LOS }\end{array}$ & 484 & 206 & $<0.001$ & 921 & 212 & $<0.001$ & 851 & 212 & $<0.001$ \\
\hline $\begin{array}{c}\text { Patients } \\
\text { died }\end{array}$ & 459 & 16 & $<0.001$ & 306 & 16 & $<0.001$ & 153 & 16 & $<0.001$ \\
\hline
\end{tabular}

ICU: Intensive Care Unit

LOS: Length of Stay 